\title{
Optimization and Evaluation Experiment of Surfactant Agent for Surfactant-Polymer Flooding System
}

\author{
Xinran Wang, Xianbo Luo, Fengjun Zhou, Gang Wang, Xiaolin Zhu
}

\begin{abstract}
In order to improve the development effect of chemical flooding in offshore oil field, the mechanism and influencing factors of Surfactant-polymer flooding system were analysed. Taking Oilfield $A$ as the research target, according to the similarity criterion, under the conditions of simulated reservoir temperature and pressure, eleven kinds of surfactants were optimized and evaluated. According to the analysis and comparison of the experimental results, Betaine, a-Olefin sulfonate and SP-4073 surfactants have good interfacial activity and solubility with formation water. The interfacial tension between surfactant and crude oil at different concentrations was measured by interfacial tension instrument, and the change trend of interfacial tension with the mass concentration of three surfactants was obtained. With the increase of surfactant mass concentration, the interfacial tension first decreases to a critical point and then increases. SP-4073 can form the lowest interfacial tension with crude oil in a wide range of mass concentration, so it becomes the most suitable surfactant for Surfactant-polymer flooding system in Oilfield A.
\end{abstract}

Index Terms - Surfactant, solubility, interfacial tension, laboratory research.

\section{INTRODUCTION}

Polymer flooding technology began in the 1950s. A large number of field applications show that polymer flooding can enhance oil recovery by $10 \%$, which is a mature enhance oil recovery technology [1-3]. Polymer flooding can increase the viscosity of water phase, improve the mobility ratio of water to oil, and stabilize the flooding front, so as to achieve the purpose of enhance oil recovery, Therefore, polymer flooding is mainly used to expand the macro sweep volume of reservoir [4-5]. However, polymer flooding usually cannot reduce the residual oil saturation, so it cannot effectively improve the micro flooding efficiency. Surfactant flooding can effectively improve micro flooding efficiency by reducing oil-water interfacial tension and changing reservoir rock surface wettability. However, surfactant has the disadvantages of high price and strong adsorption on reservoir rock surface [6-9]. Therefore, some scholars have developed Surfactant-polymer flooding system technology, which can solve the problems of single polymer flooding or surfactant flooding. Compared with single polymer flooding or surfactant flooding, the synergistic effect of polymer and surfactant can make the

Manuscript received July 01, 2021.

Xinran Wang, CNOOC China Limited, Tianjin Branch, Tianjin, China Xianbo Luo, CNOOC China Limited, Tianjin Branch, Tianjin, China. Fengjun Zhou, CNOOC China Limited, Tianjin Branch, Tianjin, China Gang Wang, CNOOC China Limited, Tianjin Branch, Tianjin, China. Xiaolin Zhu, CNOOC China Limited, Tianjin Branch, Tianjin, China. oilfield obtain higher oil recovery [10-12], so Surfactant-polymer flooding system has a good application prospect.

\section{FLOODING MECHANISM OF SURFACTANT-POLYMER FLOODING SYSTEM}

Surfactant-polymer flooding system has the functions of improving sweep volume and oil flooding efficiency, which is mainly realized by increasing the viscosity of flooding phase and reducing the interfacial tension between oil and water, thus greatly improving the oil recovery.

\section{A. Improve the Mobility Ratio of Water to Oil, Expand the Swept Volume}

The surfactant-polymer composite system has better viscoelasticity and interfacial viscosity, and improves the mobility control ability and oil carrying capacity of flooding phase. The thickening of flooding phase by composite system can reduce the diffusion rate of surfactant and the loss of surfactant.

\section{B. Reduce Oil-Water Interfacial Tension and Improving Flooding Efficiency}

When the oil-water interfacial tension decreases, the oil droplets are easy to deform, and the resistance decreases when the oil droplets pass through the pore throat. In this way, the residual oil in the highly dispersed state in the hydrophilic rock will be displaced and form flowing oil. Because the main forces causing oil droplets to be trapped in reservoir pores are viscous force and capillary force, and the ratio of viscous force to capillary force is capillary number, in order to improve micro flooding efficiency of reservoir and make trapped oil flow, capillary number must be increased from $10^{-6}$ to $10^{-2}$ and interfacial tension reduced to $10^{-3} \mathrm{mN} / \mathrm{m}$. Surfactant can reduce oil-water interfacial tension, increase capillary number and improve micro flooding efficiency of oil.

\section{Change the Wettability of Rock Surface}

When the wettability of rock surface is lipophilic, the oil flooding efficiency is low; when the wettability of rock surface is hydrophilic, the oil flooding efficiency is high. For the rock surface with hydrophilic wettability, part of the residual oil is adsorbed on the rock surface as a film.

\section{Make Oil Droplets Gather and Form Oil Belt}

With the continuous flooding of crude oil on the reservoir surface, the number of oil droplets will be more and more, the oil droplets collide with each other when they move forward. 
Surfactant-polymer flooding system can weaken the repulsive energy between oil droplets, make oil droplets gather and form oil belt. When the oil belt moves forward, it will continue to accumulate the scattered oil, make the oil belt expand and finally recover from the production wells.

\section{E. Increase the Dispersion of Crude Oil in Water Phase}

The ratio of hydrophilic group to lipophilic group of surfactant used for flooding is generally in the range of 7 18. The surfactant is adsorbed on the oil-water interface to reduce the interfacial tension between oil and water, so that the crude oil can be dispersed in the water phase to form stable oil in water emulsion. In addition, due to the adsorption of surfactant on the surface of the oil drop, the oil drop has negative charge, so it is difficult for the oil drop to be adsorbed by the rock surface. The emulsified oil droplets are not easy to be absorbed by the oil wet seepage channel when they move forward, which improves the oil flooding efficiency. The emulsified oil droplets produce superimposed Jamin effect in the high permeability layer, which can make the flooding phase advance to the production well more evenly and improve the macro sweep volume. After the residual oil is started, oil droplets of different sizes are formed for migration, and the larger oil droplets are dispersed into smaller oil droplets in the process of displacement, and the formed small oil droplets are easier to be carried and migrated by the fluid of flooding phase.

\section{EXPERIMENTAL CONDITIONS AND STEPS}

\section{A. Experimental Materials}

Experimental water: it is the formation water compounded according to the ion composition of Oilfield A's water source well, with a total salinity of $8878 \mathrm{mg} / \mathrm{L}$, and the formation water composition is shown in Table. I. The viscosity is 0.5 $\mathrm{mPa} \cdot \mathrm{s}$ at $65^{\circ} \mathrm{C}$.

Table. I Ionic composition of experimental water

\begin{tabular}{|c|c|c|c|c|c|c|}
\hline $\mathrm{K}^{+}+\mathrm{Na}^{+}$ & $\mathrm{Mg}^{2+}$ & $\mathrm{Ca}^{2+}$ & $\mathrm{Cl}^{-}$ & $\mathrm{SO}^{2-}$ & $\mathrm{HCO}^{3-}$ & Salinity \\
\hline 2420 & 185 & 697 & 5388 & 29 & 159 & 8878 \\
\hline
\end{tabular}

Experimental oil: it is composed of dehydrated crude oil from Oilfield $\mathrm{A}$ and kerosene. The ratio of crude oil to kerosene is $7.2: 1.0$. The viscosity is $10.2 \mathrm{mPa} \bullet \mathrm{s}$ at $65^{\circ} \mathrm{C}$.

Experimental polymer: the polymer actually used in Oilfield A.

Experimental surfactant: The surfactants used in surfactant polymer flooding system mainly include anionic surfactant, carboxylate surfactant, nonionic surfactant and amphoteric surfactant, and all kinds of surfactants have clear characteristics.

(1) Anionic surfactant: In the molecular structure of anionic surfactant, the ionic hydrophilic group is anion. This kind of surfactant is usually prepared from natural animal, vegetable oil and synthetic fatty acid by alkali saponification, including sulfonate, petroleum sulfonate, alkylbenzene sulfonate, lignosulfonate $\alpha$ - Olefin sulfonate, fatty alcohol polyoxyethylene ether sulfate, etc.

(2) Carboxylate surfactant: Carboxylate is divided into vegetable oil carboxylate and petroleum carboxylate. This kind of surfactant is vegetable oil carboxylate obtained from corn by fermentation and sulfonation.

(3) Nonionic surfactant: Nonionic surfactant is a kind of surfactant which can disperse in water in neutral molecular state and micelle state without dissociation of anions and cations. Because of its molecular structure is different from other types of surfactants, it not only has the common characteristics of general surfactants, but also can adapt to a larger range of $\mathrm{PH}$ value.

(4) Amphoteric surfactant: There are both anionic and cationic hydrophilic groups in these surfactants, which are amphoteric. Betaine type amphoteric surfactants are commonly used. Because of its chelating effect on metal ions, the surfactant can be used for oil displacement in reservoirs with high salinity and high temperature. It can greatly reduce the chromatographic separation effect of the mixture of nonionic and anionic surfactants. Studies have shown that amphoteric surfactants can meet the requirements of interfacial tension of surfactant polymer flooding system, but this kind of surfactant has the disadvantage of high price.

According to various surface activities and characteristics, and considering the physical properties of reservoir a in oilfield, 11 kinds of surfactants were selected, including HYFQ-A, HFFQ-B, HYFQ-C, $\alpha$-Olefin sulfonate, Sodium dodecyl benzene sulfonate, Sodium dodecyl sulfate, Sodium dodecyl sulfonate, Betaine, SP-4073, Huan-16, AG-166.

\section{B. Experimental Instruments}

The experimental instruments including TX-500C rotary drop interfacial tension meter, analytical balance, laboratory glassware, etc. The laboratory interfacial tension meter is shown in Fig. 1.

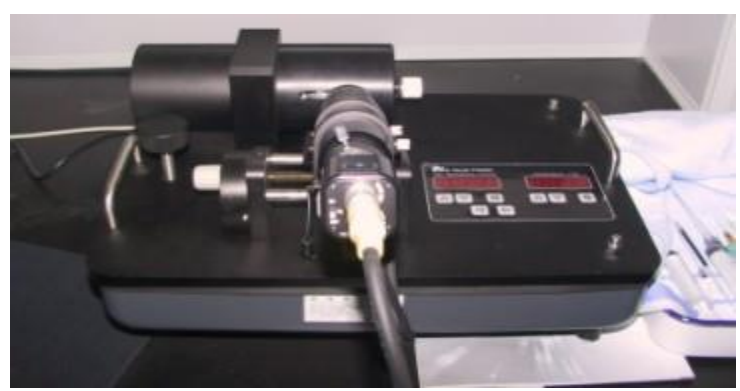

Fig. 1 TX-500C rotary drop interfacial tension meter

\section{Experimental Temperature}

The experimental temperature was $65^{\circ} \mathrm{C}$.

\section{Experimental Steps}

1) The surfactant was prepared with polymer solution $(1200 \mathrm{mg} / \mathrm{L})$ to $0.05 \%$ and $0.2 \%$ by mass;

2) Each solution was mixed with formation water of Oilfield A, and its solubility was observed after standing for 24 hours to evaluate the solubility of surfactant with formation water under formation conditions;

3) The interfacial tension between surfactant solution and formation crude oil was measured by TX-500C rotary drop interfacial tension meter, so as to optimize the surfactant with low interfacial tension. 


\section{EXPERIMENTAL RESULTS AND ANALYSIS}

\section{A. Adaptability Evaluation}

Solubility research is an important content in the optimization of surfactants. Poor solubility will seriously affect the application efficiency of surfactants. The solubility of different surfactant solutions with formation water was observed, and the interfacial tension between solution and crude oil was measured at formation temperature. The surfactant with good solubility with formation water and low interfacial tension is selected. The solubility and interfacial tension of various surfactants in the experiment are shown in Table. II.

Table. II Results of surfactant solubility and interfacial tension measurement

\begin{tabular}{|c|c|c|c|c|}
\hline \multirow{2}{*}{$\begin{array}{c}\text { Concentration } \\
/ \%\end{array}$} & $\begin{array}{c}\text { Surfactant } \\
\text { concentration is } \\
0.05 \%\end{array}$ & \multicolumn{2}{|c|}{$\begin{array}{c}\text { Surfactant } \\
\text { concentration is } \\
0.20 \%\end{array}$} \\
\cline { 2 - 5 } & Solubility & $\begin{array}{c}\text { Interfacial } \\
\text { tension } \\
/(\mathrm{mN} / \mathrm{m})\end{array}$ & Solubility & $\begin{array}{c}\text { Interfacial } \\
\text { tension } \\
/(\mathrm{mN} / \mathrm{m})\end{array}$ \\
\hline $\begin{array}{c}\text { Sodium } \\
\text { dodecyl } \\
\text { benzene } \\
\text { sulfonate }\end{array}$ & 5.85 & & 4.25 \\
\hline $\begin{array}{c}\text { Sodium } \\
\text { dodecyl } \\
\text { sulfate }\end{array}$ & Turbidity & -- & Turbidity & -- \\
\hline $\begin{array}{c}\text { Sodium } \\
\text { dodecyl } \\
\text { sulfonate }\end{array}$ & & 5.36 & & 5.49 \\
\hline Betaine & & 0.95 & & 0.05 \\
\hline $\begin{array}{c}\alpha-\text { Olefin } \\
\text { sulfonate }\end{array}$ & & 0.82 & & 0.10 \\
\hline SP-4073 & & 0.53 & & 0.01 \\
\hline HYFQ-C & & 3.57 & & 0.35 \\
\hline HYFQ-B & & 2.49 & Turbidity & -- \\
\hline HYFQ-A & & 3.57 & Turbidity & -- \\
\hline Huan-16 & & 4.76 & & 1.69 \\
\hline AG-166 & & 2.01 & & 0.62 \\
\hline
\end{tabular}

According to the experimental results, Sodium dodecyl sulfate, HYFQ-B and HYFQ-A appear turbidity after mixing with formation water, which indicates that these surfactants have poor solubility with formation water. Although Sodium dodecyl benzene sulfonate, Sodium dodecyl sulfonate, HYFQ-C, Huan-16 and AG-166 have good solubility with formation water, they cannot obtain lower interfacial tension.

According to the experiment results, Betaine, $\alpha$-Olefin sulfonate and SP-4073 surfactants can obtain lower interfacial tension. When the mass concentration is $0.20 \%$, the interfacial tension between oil and binary system solution can reach the order of $10^{-2} \mathrm{mN} / \mathrm{m}$, and they have good solubility with formation water without precipitation. Therefore, the three surfactants were selected to optimize the mass concentration.

\section{B. Optimization of surfactant mass concentration}

In order to obtain the most suitable surfactant polymer flooding system solution concentration for Oilfield A. The concentration optimization of three kinds of surfactant with low interfacial tension was studied. The interfacial tension between formation water, polymer solution and crude oil was measured by mixing three kinds of surfactant solutions with different concentrations. According to the determination, the most suitable surfactant and its concentration were selected.

Prepare polymer solution with formation water with concentration of $1200 \mathrm{mg} / \mathrm{L}$. The polymer solutions with concentration of $0.05 \%, 0.10 \%, 0.20 \%, 0.30 \%$ and $0.40 \%$ were prepared with the selected surfactant. The interfacial tension between polymer solution and crude oil in Oilfield $\mathrm{A}$ was measured by means of interfacial tension meter at $65^{\circ} \mathrm{C}$;

The test results of interfacial tension between surfactant with different concentrations and formation water are shown in Fig. 2. The interfacial tensions between the three surfactants and crude oil first decrease and then increase with the increase of surfactant concentration. It is not that the higher the surfactant content is, the lower the oil-water interfacial tension is. This is because when the oil-water interfacial tension reaches the lowest, a large number of surfactant molecules gather at the oil-water interface, and the force of molecules at the oil-water interface reaches dynamic equilibrium. As the concentration of surfactant continues to increase, the number of surfactant molecules in the system increases, and the molecular force balance is destroyed, resulting in the increase of interfacial tension.

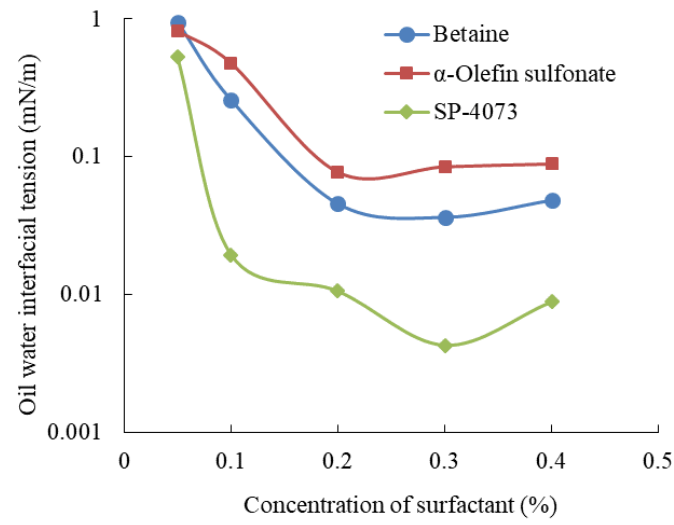

Fig. 2 Interfacial tension between surfactant of different concentration and oil

The experimental results show that in a large concentration range, surfactant SP-4073 can form the lowest interfacial tension with crude oil. When the concentration range is from $0.20 \%$ to $0.40 \%$, the interfacial tension can be as low as $10^{-2}$ $\mathrm{mN} / \mathrm{m}$, so it has good interfacial activity.

\section{FIELD APPLICATION}

In the early stage of Oilfield A development, artificial water flooding was used. Water flooding development can maintain formation pressure, but the strong heterogeneity of formation leads to serious water channeling after water flooding. The effective period of the measures to control water channeling is very short, so the pilot experiment of polymer flooding was carried out in Oilfield A in 2007. It can be seen from Fig. 3 that the water cut of oilfield begins to 
decrease after polymer flooding. However, three years after polymer flooding, the water cut of oilfield began to rise faster. Therefore, based on polymer flooding, the study on surfactant-polymer flooding is carried out in the oilfield. According to the results of this study, SP-4073 was selected as the surfactant. Oilfield A officially started to change the development mode from polymer flooding to surfactant-polymer flooding in 2012. After the surfactant-polymer flooding, the water cut of the oilfield decreases again, the oil production of the oilfield increases, and the development effect of the oilfield is greatly enhanced. The field test shows that the application of SP-4073 in Oilfield A is effective.

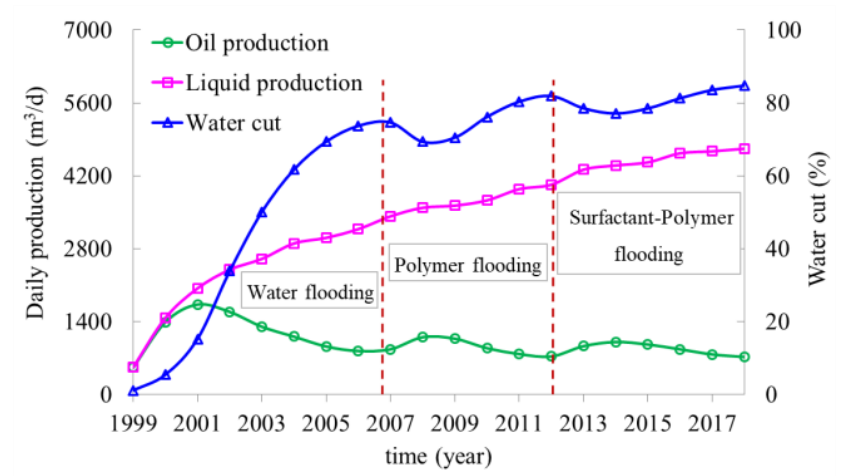

Fig. 3 Production performance of Oilfield A

Include a note with your final paper indicating that you request color printing. Do not use color unless it is necessary for the proper interpretation of your figures. There is an additional charge for color printing.

\section{CONCLUSIONS}

Through this study, we can get the following conclusions:

1) According to the surfactant solubility and interfacial tension measurement laboratory research, when the mass concentration is $0.20 \%$, the surfactant Betaine, $\alpha$-Olefin sulfonate and SP-4073 have good solubility with formation water. The interfacial tension between the three surfactants and crude oil can reach the order of $10^{-2}$ $\mathrm{mN} / \mathrm{m}$.

2) The interfacial tension between the selected surfactant and crude oil first decreases and then increases with the increase of surfactant concentration, when the concentration of SP-4073 and polymer is between $0.20 \%$ and $0.40 \%$, the lowest interfacial tension can be formed with crude oil. Therefore, it is selected as the most suitable surfactant for Oilfield A.

3) According to the field practice of surfactant polymer flooding in Oilfield A, The application of the surfactant selected in this study can reduce the water cut and increase the oil production, so as to improve the oilfield development effect, which shows that the research results are reliable. during EOR Polymer Flooding Using Micromodels. World Journal of Engineering and Technology, 6, 332-349.

[2] Fan, Z., Wang, M., Jigang, J. and Wang, X. (2015) Study on Oil Displacement Efficiency of Binary Compound Flooding in Heterogeneous Reservoir. Energy and Power Engineering, 7, 571-574

[3] Tahir, M., Hincapie, R., Be, M. and Ganzer, L. (2017) A Comprehensive Combination of Apparent and Shear Viscoelastic Data during Polymer Flooding for EOR Evaluations. World Journal of Engineering and Technology, 5, 585-600.

[4] Wang, X. , Ge, L. , Liu, D. , Zhu, Q. and Zheng, B. (2019) Experimental Study on Influencing Factors of Resistance Coefficient and Residual Resistance Coefficient in Oilfield Z. World Journal of Engineering and Technology, 7, 270-281.

[5] Seright, R.S., Fan, T., Wavrik, K.E. and Balaban, R.D.C. (2010) New Insights into Polymer Rheology in Porous Media. SPE-129200-PA.

[6] Y. Li and L. Yin, "A New Surfactant Flooding Model for Low Permeability Reservoirs," Open Journal of Fluid Dynamics, Vol. 3 No. 1, 2013, pp. 1-8.

[7] D. Yin, P. Gao and H. Pu, "Investigation of a New Simulator for Surfactant Floods in Low Permeability Reservoirs and Its Application in Chao-522 Field, 2010 Update," SPE 128645, Presented at the 2010 SPE EOR Conference at Oil \& Gas West Asia, Muscat, 11-13 April 2010.

[8] Kerunwa, A. (2020) The Impact of Core Firing on EOR of Low Salinity-Surfactant Flooding. Open Journal of Yangtze Oil and Gas, 5, 103-116.

[9] Cuiec, L., Bourbiaux, B. and Kalaydjian, F. (1994) Oil Recovery by Imbibition in Low-Permeability Chalk. SPE formation Evaluation, 9, 200-208.

[10] Liu Zheyu, Li Yiqiang, Leng Runxi, Liu Zhenping, Cheng Xin, Hejazi Hossein. Effects of pore structure on surfactant/polymer flooding-based enhanced oil recovery in conglomerate reservoirs. Petroleum Exploration and Development, 2020, 47(1).

[11] Yefei Wang,Zongyang Li,Mingchen Ding,Qun Yu,Dong Zhong,Xulong Cao. Performance of a good- emulsification- oriented surfactant- polymer system in emulsifying and recovering heavy oil. Energy Science \& Engineering, 2020, 8(2).

[12] Chemistry; Studies from PetroChina Company Ltd. Describe New Findings in Chemistry (3D Physical Simulation Experiment of Edge Water Reservoir by Polymer/Surfactant Binary Flooding). Energy Weekly News, 2020

Xinran Wang senior engineer, master's degree, mainly engaged in oil and gas field development research.

Xianbo Luo professor level senior engineer, doctor's degree, mainly engaged in oil and gas field development research.

Fengjun Zhou senior engineer, master's degree, mainly engaged in oil and gas field development research.

Gang Wang senior engineer, master's degree, mainly engaged in oil and gas field development research.

Xiaolin Zhu senior engineer, bachelor's degree, mainly engaged in oil and gas field development research.

\section{REFERENCES}

[1] Knobloch, L.O., Hincapie, R.E., Foedisch, H. and Ganzer, L. (2018) Qualitative and Quantitative Evaluation of Permeability Changes 